\title{
Bifurcaciones biográficas en los escenarios laborales del Chile contemporáneo: una comparación entre trabajadores del retail y emprendedores sociales
}

Biographical bifurcations in the workplace of contemporary Chile: a comparison between retail workers and social entrepreneurs

\section{Rodolfo Martinic Lenta}

Doctorante en sociología École des Hautes Études en Sciences sociales, Francia ANID - Programa Iniciativa Científica Milenio - Núcleo Milenio Autoridad y Asimetrías de Poder

\section{Ismael Tabilo Prieto}

Universidad Alberto Hurtado, Facultad de Psicología, Santiago, Chile

RESUMEN El presente artículo analiza y compara las bifurcaciones de trabajadores asalariados e independientes vinculados a escenarios laborales con amplios contrastes entre ellos, considerados como formas de empleo prototípicas del Chile contemporáneo. Por un lado, el de una tradicional tienda por departamento del país, que en las últimas décadas experimentó un proceso de restructuración que la transformó en una de las empresas más importantes del retail chileno. Por otro lado, el de los emprendimientos de innovación social, una forma de autoempresa que añade al espíritu emprendedor la preocupación por problemáticas sociales. A través de las herramientas teóricas de la sociología del curso de vida y de las bifurcaciones biográficas, se analizaron 32 entrevistas en profundidad con el fin de comprender la experiencia de los trabajadores al momento de entrar en una categoría laboral improbable o inesperada en relación a la situación laboral anterior. Los resultados muestran que las experiencias de bifurcación en cada escenario varían significativamente en función del vínculo al trabajo y el vínculo al empleo. Mientras que en el retail, el ingreso está marcado por una decisión adaptada a la escasez de alternativas disponibles que con el tiempo da lugar a una valorización del empleo que con- 
trasta con una insatisfacción con el trabajo, en el emprendimiento se evidencia un esfuerzo por reorientar la propia experiencia profesional en busca de una mayor realización en el trabajo, sacrificando la estabilidad del empleo. En las conclusiones, se interpretan las diferencias y similitudes de las bifurcaciones biográficas a la luz de las transformaciones del Chile actual.

PALABRAS CLAVES Bifurcaciones biográficas; curso de vida; retail; emprendimientos de innovación social.

ABSTRACT This article explores and compares the labor bifurcations of salaried and independent workers in contrasting labor scenarios that are representative of prototypical forms of employment currently widespread in Chile. On the one hand, that of a traditional department store which in the last decades has undergone a restructuring process that transformed itself into one of the most important Chilean retail companies. On the other hand, that of social innovation ventures, a form of business that brings together the entrepreneurial spirit with a declared interest in social problems. Through the theoretical tools of life-course sociology and biographical bifurcations, we analyze indepth 31 interviews to study the experience of workers entering a job category that differs from their educational trajectories and/or previous work. The results show that the experience of bifurcation varies according to the setting. While in retail there is an orientation towards adaptive preference, a valuing of stable employment, and dissatisfaction with the work they have to do, the entrepreneurship model shows attempts to shape one's own professional experience, which articulates with a precarious attachment to employment and an attempt to fulfill one's expectations at work. In the conclusions, we interpret the bifurcations of each scenario in the light of the transformations currently happening in Chile, seeking to establish their differences and similarities.

KEYWORDS Biographical bifurcations; life course; retail; social innovation ventures.

\section{Introducción}

En las últimas cuatro décadas, las transformaciones institucionales de la sociedad chilena expresadas en el tránsito desde formas estado-céntricas hacia estructuras crecientemente mercado-céntricas, han impactado fuertemente en el ámbito laboral. En efecto, el crecimiento económico y aumento del empleo que experimentó el país, fue acompañado de la fragmentación del mundo del trabajo por los procesos de flexibilización y desregulación laboral, debilitando el lugar de éste como fuente de identidades colectivas, mermando la capacidad de organización sindical y disminuyendo el 
poder de negociación de los trabajadores en las empresas (Cárdenas, Link \& Stillerman, 2012; Wormald y Trebilcock, 2015). Estas transformaciones, que se inscriben dentro de los cambios económicos, organizacionales y tecnológicos de las formas de capitalismo contemporáneo, han modificado la configuración de los escenarios y trayectorias laborales.

El presente artículo interroga dos escenarios laborales que se han perfilado en el Chile actual como prototípicos del país tanto por su crecimiento en términos de empleo como por su pregnancia en el imaginario nacional: las tiendas por departamento de "industria del retail" (Stecher, 2013) y los emprendimientos de innovación social. A través de la noción de "bifurcación biográfica", analizamos y comparamos el momento del curso de vida de los individuos que comprende el ingreso a cada una de estas situaciones laborales. Examinando la interacción entre los elementos estructurales y subjetivos de este proceso, se busca iluminar el quiebre biográfico que implica la inserción laboral o la creación de una empresa a partir de la reflexividad de los actores, así como también dar cuenta de los vínculos al empleo y al trabajo que despliegan en el momento de la ruptura. Respecto a esto último, la comparación que llevamos a cabo evidencia cómo se construyen en el tiempo dos formas de integración profesional que se oponen en sus términos (Paugam, 2007): una integración laboriosa caracterizada por un vínculo al empleo estable y uno al trabajo predominantemente insatisfactorio en el retail y una integración incierta fundada en un vínculo inestable al empleo, pero en uno de realización en el trabajo en el caso los emprendedores sociales.

Nuestra investigación se ubica dentro del campo de sociología del curso de vida ${ }^{1}$. El análisis biográfico a través de la noción de curso de vida implica un distanciamiento respecto a la de trayectoria, más frecuentemente utilizada en ciencias sociales. Mientras que esta última se sustenta en la metáfora balística asociada a un camino predeterminado cuyo curso es mantenido por disposiciones que se van actualizando con el paso del tiempo, el curso de vida deja abiertos senderos transversales, cambios de dirección, dando espacio a la reflexividad del actor y a la posibilidad de apropiarse de su propio recorrido (Zimmermann, 2014). Así, si la trayectoria enfatiza el predominio de la posición social y de las disposiciones individuales asociadas en un desarrollo biográfico que se encuentra - más o menos - determinado, el curso de vida pone el acento en la capacidad de actuar de las personas en las diferentes etapas y circunstancias de la vida.

En ese sentido, la noción de curso de vida abre una perspectiva de análisis alternativa a enfoques en el campo de los estudios del trabajo en América Latina que se enmarcan dentro de la lógica de la trayectoria. Por un lado, en los estudios sobre

1. Hemos traducido como curso de vida lo que en las ciencias sociales anglosajonas se denomina life course y en las francesas parcours de vie. 
trayectorias laborales suele observarse un uso difuso de esta noción, siendo fácilmente intercambiable por otros de cercanía semántica como recorrido, itinerario o carrera. Pareciera que el concepto muchas veces se asume de manera autoevidente, apelando probablemente a su conocimiento extendido en el habla cotidiana, sin una clara operacionalización y con la finalidad de organizar temporalmente un amplio registro de las experiencias laborales. Por otro lado, la noción de trayectoria se vincula a estudios que por medio de metodologías cuantitativas describen los cambios en la situación laboral y la ocupación de la población activa. Revelando la precarización de las posiciones ocupacionales producto de los procesos de flexibilización empresarial, organizacional y laboral en el marco de la crisis de protección del empleo y el trabajo (Henríquez \& Uribe-Echevarría, 2004), algunos estudios asumen perspectivas de género (Abramo, 2004; Todaro \& Yáñez, 2004) o de brechas generacionales (Weller, 2007) para mostrar las desigualdades que afectan a grupos sociales como las mujeres y los jóvenes. Aunque logra describir las transformaciones ocupacionales en grandes poblaciones, la investigación hace de la biografía algo mecánico, más centrada en los cambios que enfrentan los trabajadores desde nivel macro y menos en la experiencia y perspectiva que tienen los actores.

En este artículo, utilizamos la sociología del curso de vida para analizar las relaciones entre lo "sociológico" y lo "biográfico", mostrando cómo los recorridos se iluminan al estar vinculados a procesos sociohistóricos y cómo, a la inversa, estos procesos pueden comprenderse a partir del análisis de sus traducciones individuales (Dubar \& Nicourd, 2017). Entre estas relaciones posibles, el artículo se centra en una en particular: la bifurcación biográfica experimentada en un cambio ocupacional en dos escenarios laborales diferentes. El primero de los cinco apartados del artículo - sin considerar esta introducción - está dedicado a la contextualización y fundamentación de la perspectiva del curso de vida y de las bifurcaciones biográficas. En el siguiente, se caracterizan los dos escenarios laborales estudiados y se presenta un breve estado del arte sobre los recorridos laborales de sus trabajadores, para enseguida exponer el diseño metodológico tanto del artículo como de las investigaciones que lo conforman. En el cuarto apartado, las bifurcaciones biográficas en ambos escenarios son analizadas a través de una presentación que diferencia entre el "antes" y el "después" del ingreso. Finalmente, en la discusión se establecen las principales diferencias y puntos en común de ambos escenarios en el contexto de las transformaciones del trabajo recientes del país.

\section{La sociología del curso de vida y las bifurcaciones biográficas}

El enfoque del curso de vida toma forma en las décadas de los 70' de la mano de autores como Elder (1974) y Riley (1979) quienes a través del estudio de infancia y de la vejez comienzan a preguntarse por el impacto de la historia y de los factores ge- 
neracionales en las biografías. Sus trabajos enfatizaron el hecho de que las personas que componen una población no sólo son más jóvenes o mayores, sino que también tienen experiencias históricas y sociales diferentes en la medida que sus socializaciones se desarrollaron en espacios-tiempos diferentes (Dubar \& Nicourd, 2017). Hoy en día, casi medio siglo después, este tipo de sociología propone una perspectiva que busca mover el foco de análisis desde las estructuras hacia las dinámicas de los fenómenos sociales (Fleury \& Raïq, 2013) o, en otras palabras, desde las entidades que la componen hacia los procesos que las construyen (McDaniel \& Bernard, 2011).

El curso de vida reposa en una concepción de la vida humana entendida como un guion más o menos flexible, con diferentes etapas y eventos relacionados entre sí, que provocan cambios de estatus y roles los cuales van orientando las biografías (Guichard Concha, Henríquez, Cavalli y D'epinay, 2013). Este guion, que dicta las reglas que organizan la vida social, da cuenta de la "institucionalización del curso de vida" en las sociedades modernas (Kohli, 1989). Este proceso designa una unidad contradictoria que reviste tres dimensiones: la normalización del curso de vida, en el sentido de la evolución de una secuencia cronológica con etapas bien definidas, la creación de una vida previsible con una gran medida de seguridad (paso de un régimen de muerte imprevisible a uno de duración previsible) y, la génesis de un código de desarrollo personal, bajo el cual la vida deviene un proyecto personal que cada uno tiene que decidir. La evolución de la institucionalización del curso de vida ha funcionado principalmente de acuerdo al sistema de trabajo - estableciendo una partición neta en un periodo de preparación, de vida activa - y, a la vez, está íntimamente ligado al proceso de individualización. Así, una sociología del curso de vida tiene como objetivo analizar la manera mediante la cual las sociedades organizan el desarrollo de las vidas humanas, con ayuda de modelos establecidos. Modelos que evolucionan y producen un trabajo de deconstrucción y reconstrucción permanente (D'Epinay, Bickel, Cavalli y Spini, 2005, p. 67).

En este contexto, Fillieule (2001) delimita dos tipos de cambios biográficos: los institucionales, cambios de status asociados a las etapas institucionalizadas de la vida, y los accidentes biográficos, provocados por eventos como crisis, fracasos o duelos. Mientras que los primeros poseen un cierto nivel de previsibilidad en razón de la institucionalización de las etapas "normales" de una biografía, los segundos implican un momento de suspensión de los proyectos de acción, una suerte de desapego o "moratoria del compromiso" (Mazade, 2011). Dentro de los accidentes biográficos, existen al menos dos etapas complementarias. Por un lado, la desidentificación, proceso en el cual el curso de acción pierde el sentido que había tenido hasta ese momento y, por otro lado, la iniciación, en el cual se retoma el curso de acción y el compromiso con el proyecto biográfico en definición. Ambos procesos resaltan la existencia de eventos biográficos impredecibles que pueden producir cambios durables e irreversibles en los motivos, representaciones y actitudes de las personas. 
El interés que han cobrado las bifurcaciones biográficas en sociología está ligado a la vez a los cambios en el mundo social, con la complejización de las transiciones en los ciclos de vida, y a las evoluciones de las ideas científicas. En relación a esto último, teorías como la teoría de sistemas han ejercido una influencia al mostrar cómo pequeñas diferencias en un punto de un proceso, pueden provocar grandes variaciones en los estados del sistema en una fase posterior (Bessin, Bidart \& Grossetti, 2009). Aquello es válido también en sociología, pues el descuido de lo accidental en los modelos estadísticos niega la imprevisibilidad que puede influir en las regularidades que se consideran importantes.

Por bifurcación biográfica se alude a "configuraciones en las cuales eventos contingentes o ligeras perturbaciones pueden ser la fuente de reorientaciones importantes en las trayectorias individuales o en procesos colectivos" (Bessin et al., 2009, p. 10). En el ámbito laboral, esta perspectiva ha dado lugar a relevantes investigaciones. Enfocándose en la entrada a la adultez de los jóvenes mediante el ingreso al mercado laboral, Bidart (2006) estudió el proceso decisional en trayectorias que enfrentaron cambios (de rama de actividad, de estudios, de empleo o de orientación profesional) que no obedecieron a lo esperable según los entrevistados. El carácter longitudinal de su estudio cualitativo permitió evidenciar las diferentes lógicas de elección o "ingredientes" movilizados en la toma de decisiones cuya conjunción permite la ruptura del orden social esperado. La bifurcación es entonces "un cambio importante y brutal en la dirección de la trayectoria, cuyo momento y resultado eran imprevisibles" (Bidart, 2006, p. 31).

En su investigación sobre las reconversiones profesionales voluntarias, Negroni (2007) estudió a hombres y mujeres adultos que llevaban más de cuatro años en sus lugares de trabajo y que estaban en un periodo de reorientación profesional o en búsqueda de otro empleo. Poniendo el acento en el trabajo sobre sí mismo que realizaban los trabajadores durante un cambio voluntario de status profesional, su trabajo evidencia el intenso "forcejeo" con las diferentes limitaciones sociales que intentan sobrepasar a fin de poder utilizar sus recursos para actuar sobre sus biografías. El análisis permite constatar cómo las bifurcaciones comprometen a los actores según la forma en que éstas se presentan: como proyectos, crisis, decisiones o eventos exteriores involuntarios.

También en el ámbito de la reconversión profesional, Denave (2015) explora las condiciones de posibilidad que facilitan el involucramiento con el desarrollo de un curso de acción determinado. A través de entrevistas biográficas con hombres y mujeres adultas que habían experimentado un cambio de oficio o profesión entre 1980 y 2002, Denave constata la importancia de las desigualdades sociales y de género al momento de enfrentar las rupturas biográficas. Las bifurcaciones se desarrollan según una dinámica propia animada por la interacción entre disposiciones individuales 
y contextos de acción. En base al entrecruzamiento de las historias laborales y familiares de los entrevistados, la investigadora da cuenta de cómo las reconversiones profesionales eran una forma de asegurar una continuidad individual, es decir, una manera de cambiar para no cambiar.

\section{Caracterización de los escenarios y recorridos laborales de los trabajadores}

A continuación, se describen las principales características de los dos escenarios laborales sobre los cuales se centra la investigación. En cada escenario se hace alusión a tres elementos: los antecedentes generales del rubro, una caracterización del escenario concreto estudiado en este artículo y una breve revisión bibliográfica sobre los recorridos laborales.

\section{Las tiendas por departamento en Chile}

El rubro del retail en Chile representa uno de los sectores de mayor crecimiento y dinamismo de la economía nacional en las últimas décadas, llegando a convertirse en uno de los principales empleadores del país (aproximadamente 500.000 empleados) (Soto, Stecher y Frías, 2021). Desde 1990, su constante restructuración a través de la adaptación de formas de organización y gestión en boga como el enfoque lean - orientado a disminuir costos económicos - fue acompañada la racionalización y tecnologización de toda su cadena de suministro (supply chain), así como de la profesionalización de sus cuadros (Calderón, 2006). Estas transformaciones permitieron la ampliación de los nichos de negocio de la industria y su internacionalización en América Latina, al punto de llegar a ser las empresas chilenas que emplean más trabajadores en el extranjero (Martinic, 2019; Stecher y Martinic, 2018).

Las tiendas por departamento, uno de los escenarios de este estudio comparativo, corresponden a uno de los canales de negocio mediante el cual operan los holdings empresariales del retail en Chile, y consisten en establecimientos que ofrecen una gama amplia de bienes de consumo durables organizados en "departamentos" como vestuario, electrodomésticos, línea blanca, entre otros. En tanto canal de negocio, se caracteriza por su alto nivel de penetración y maduración en el mercado chileno, el cual, pese a estar constituido por una variedad de actores (Falabella, Cencosud, Ripley, Hites, Forus, La Polar y Abcdin), se encuentra concentrado en los tres primeros (74\%) (Güell y Meschi, 2013; Martinic, 2019).

$\mathrm{Al}$ año 2015, la empresa estudiada en esta investigación contaba con 16.058 trabajadores, dentro de los cuales el $88 \%$ corresponden a cargos directamente vinculados a la venta. Del total, el $65 \%$ corresponde a mujeres y el $45 \%$ a jóvenes menores de 30 años, lo que habla de una fuerza de trabajo feminizada, principalmente joven y de bajo nivel de calificación. Como se ha evidenciado, la contratación de una mano de obra más joven y menos calificada iría de la mano con las transformaciones de la 
organización del proceso de trabajo que han implicado una mayor estandarización y rutinización de las tareas y una disminución de los salarios (Stecher \& Martinic, 2018). Por su parte, las tiendas también presentan una alta rotación de su personal (aproximadamente 51\%), la que es explicada en los reportes empresariales en razón de la juventud de los empleados. Finalmente, respecto a las condiciones laborales, el $85 \%$ de los trabajadores de la empresa se encuentra con contrato indefinido y en promedio la remuneración que obtienen es de 1,4 veces el ingreso mínimo legal.

En cuanto a los recorridos laborales de los trabajadores del retail, Martinic y Stecher (2020) constatan un contraste entre el tipo de trayectorias laborales previas de los empleados de las tiendas por departamento - discontinuas, desarticuladas y alejadas de la representación de una carrera laboral ascendente y protegida - y la estabilidad y los beneficios de la situación de empleo. A raíz de este contraste, la inserción en las empresas sería experimentada como una vía de integración social de cuatro formas diferentes: estatutaria; asociada a una situación de empleo formal con contrato indefinido; ligada a sociabilidad de las tiendas (clientes, colegas, jefes) y al lugar simbólico de estas en los imaginarios de la sociedad de consumo; formativa, por la posibilidad de adquirir aprendizajes tanto por el ejercicio cotidiano del cargo como por las capacitaciones ofrecidas, y promocional, vinculada a las oportunidades de desarrollo de carrera dentro de la organización.

Los recorridos que posteriormente se desarrollan en la empresa dan lugar, según los autores, a tres figuras de la experiencia social: comprometida, bloqueada y en tránsito. Mientras que la primera se caracteriza por la realización en el trabajo favorecida por el logro de la promoción interna y por el despliegue de una orientación estratégica hacia la obtención de los incentivos del trabajo, la segunda se asocia al cansancio, al desgaste y a la frustración de no haber ascendido, y a la predominancia de una estrategia defensiva de lo alcanzado y en un vínculo instrumental. La experiencia en tránsito, por último, se vincula con formas de socialización laboral débiles y por un distanciamiento respecto de la cultura corporativa producto de la incompatibilidad del trabajo con los estilos de vida y por anhelos de desarrollo profesionales alejados al retail.

Estas figuras de la experiencia presentan resonancias con las orientaciones subjetivas de los jóvenes en el retail estudiadas por Soto, Stecher y Frías (2021). De acuerdo a los autores, estas orientaciones dan lugar a cuatro representaciones del futuro en los trabajadores jóvenes: el futuro escindido, entre quienes se mantienen desarrollando estudios profesionales paralelamente a su empleo; el futuro capitalizado, entre quienes tienen un mayor nivel educacional y trabajan en áreas que permiten mayor autonomía y exigen el manejo de conocimiento técnico de los productos; el futuro de ensueño, entre quienes conservan proyecciones laborales optimistas fuera del rubro, pero un desarrollo concreto de sus planes de movilidad; y el futuro bloqueado, entre 
quienes los proyectos se encuentran fuertemente anclados en un presente marcado por el sacrificio y por esfuerzos de sobrevivencia cotidiana.

Siguiendo a Stecher \& Soto (2019), podríamos sostener la hipótesis de que los recorridos laborales en la industria del retail tienen como telón de fondo las transformaciones de las identidades laborales que han tenido lugar en Chile a partir de los años 80 . Según los autores, los procesos de construcción de identidad en el trabajo se configuran entre ciertos referentes que evidencian la amenaza permanente de las antiguas identidades de oficio, debido al debilitamiento de los soportes colectivos propios de la matriz nacional-popular del siglo XX y la emergencia de nuevas construcciones identitarias más individualizadas y orientadas tanto al cumplimiento de objetivos como al desarrollo de competencias.

Recapitulando, los estudios sobre el retail destacan el rol de estas empresas en la integración de grupos sociales situados en posiciones subalternas que suelen ver dificultades en sus posibilidades de inserción laboral. Esta integración, que funciona a niveles diferentes, sin embargo, es contrarrestada por un trabajo intenso tanto en términos de carga de trabajo como de exigencias temporales. Esto parece dar lugar al despliegue en el tiempo de un abanico diverso de recorridos al interior de la empresa en función del momento en el ciclo de vida y el género.

\section{La actividad emprendedora como escenario laboral}

$\mathrm{Al}$ año 2019, el 23,1\% de las personas ocupadas en Chile se dedicaban al microemprendimiento como actividad única, del cual el $61,4 \%$ corresponde a hombres. Del total de personas dedicadas al microemprendimiento, un $81,9 \%$ de los hombres se encontraba previamente trabajando como asalariado, cifra que baja a un $69,8 \%$ en el caso de las mujeres (INE, 2020). Según el informe GEM (2019) los niveles de emprendimiento en Chile reflejarían "la capacidad y espiritu emprendedor de la población chilena" (p. 6). No obstante, una mirada más detallada a partir de los datos de la última encuesta de microemprendimiento, evidencia que los microemprendedores desarrollan sus actividades principalmente de manera informal, obtienen bajos ingresos y generan bajos niveles de empleo formal (INE, 2020).

La noción de emprendimiento incluye una vasta diversidad de tipos de negocios, actividades y estructuras organizativas. Este estudio se centra en lo que comúnmente se denomina como emprendimiento "social", de "innovación", hub's creativos o "startup" agrupados principalmente en "ecosistemas de innovación social". Para esta investigación se trabajó con dos de estos ecosistemas en la región metropolitana, los cuales agrupan unos cuarenta emprendimientos en total, en distintos niveles de desarrollo, pero todos en etapas iniciales y con menos de 10 empleados al momento de realizar el trabajo de campo. 
Los emprendimientos sociales son: "organizaciones con misión social que utilizan mecanismos de mercado para la creación de valor. Se focalizan en la creación de negocios para servir a sectores desaventajados de la sociedad, quienes utilizan innovación inclusiva para resolver problemas y generar cambio social” (Muñoz, Kimmitt, Serey y Velázquez, 2016, p. 7). Esta definición delimita dos elementos claves que constituyen la principal diferencia entre un emprendimiento social y uno comercial: su proceso productivo orientado a la producción de valor social y el foco del modelo de negocios, el cual se centra en resolver de manera creativa una problemática de una comunidad o grupo social específico (Austin, Stevenson \& Wei-Skillern, 2006; Bargsted, 2013; García Alonso, Thoene, Figueroa y Murillo, 2020). Muñoz et al. (2016), registraron más de 500 emprendedores - socios fundadores o activamente involucrados en la creación de este tipo de empresas-, lo que evidencia que estas iniciativas se concentran principalmente en la región metropolitana y que más de la mitad de las organizaciones (57\%) se forma con la intención de resolver problemas sociales.

En cuanto a las formas de inserción y los recorridos laborales de las personas emprendedoras, los estudios sobre la disposición a involucrarse en este tipo de proyectos suelen enfocarse en aspectos individuales como la identidad, la personalidad y el carácter del emprendedor (Martínez, 2010; Sastre, 2013; Schoof, 2006). Sin embargo, Knox, Casulli \& MacLaren (2021) dan cuenta que, en los emprendimientos creativos, la identidad del emprendedor se construye en función de la cercanía o intimidad con los demás, la experiencia compartida y la posibilidad de co-crear un compromiso mutuo. No así en los emprendimientos comerciales en donde en el trabajo identitario se realiza en base a la jerarquía y el rol que se ocupa en la organización. En consecuencia, el compromiso con los otros suele estar orientado por valores más instrumentales y utilitarios.

La creación de una nueva empresa produce una serie de desequilibrios, generando la necesidad de ajustar los proyectos de vida en las distintas etapas de su creación (Bueno Castellanos, 2020). Así, como proyecto biográfico-laboral, el emprendimiento es un proyecto que permea las otras esferas de la vida (Pries, 1999), desbalanceando los diferentes roles que las personas cumplen en cada una de ellas. Este desbalance resulta ser especialmente conflictivo en el caso de las mujeres (Suárez Ortega, Sánchez-García \& Soto-González, 2020), debido a la tensión con el trabajo doméstico, tradicionalmente asignado a ellas, y al peso de los roles de género, los cuales limitan el emprendimiento y la actividad empresarial a los hombres (Naranjo, 2014).

Intervienen en este recorrido las situaciones familiares, los círculos de pares (que pueden animar o desanimar este tipo de carrera), los proyectos de vida, como querer ser autónomo, manejar el propio tiempo o no tener jefe, o situaciones laborales como el estancamiento de la carrera, periodos extendidos de cesantía, insatisfacción en el trabajo, u otras formas de incertidumbre laboral (Barthe, Chauvac \& Grossetti, 
2016; Grossetti y Barthe, 2008; Grossetti, 2016). En el caso específico de los llamados start-up o emprendimientos de innovación, los fundadores o fundadoras, lejos de ser genios creadores individuales, se apoyan principalmente en sus redes personales (Bueno Castellanos, 2020) y suelen comenzar la actividad de manera grupal (Grossetti, Barthe y Chauvac, 2018).

Por último, los análisis sobre la capacidad de agencia y la racionalidad emprendedora dan cuenta de un entramado de disposiciones, situaciones y reacciones que delimitan y orientan este recorrido. Según Bueno Castellanos (2020), la agencia de los emprendedores no viene definida completamente por sus experiencias laborales previas. Esta se complementa y modifica con nuevas habilidades, redes y contactos que se van construyendo en el devenir emprendedor. Para Reix y Grossetti (2014), el compromiso con una carrera emprendedora remite en realidad a una pluralidad de motivos vinculados a diferentes lógicas de acción, dentro de las cuales destacan: ganar estatus social (lógica de integración), maximizar los propios recursos (lógica estratégica) y realizarse como sujeto (lógica subjetiva).

Esta breve revisión de los recorridos y las formas de inserción de las personas en este tipo de proyectos profesionales, nos permite comprender que la categoría "emprendedor" envuelve una enorme diversidad de identidades, motivaciones y proyectos de vida, los cuales además difieren entre culturas y contextos sociales específicos (Bell et al., 2019). Estas perspectivas nos ayudan a complementar la tradicional imagen del emprendedor individual con habilidades específicas para identificar oportunidades de negocios. El proceso emprendedor implica desbalances importantes en la vida cotidiana, reajustes, reevaluaciones y un activo uso de los recursos sociales y materiales para la conformación de la propia actividad.

\section{Metodología}

El artículo se basa en dos investigaciones llevadas a cabo por cada uno de los autores, las cuales son independientes una de la otra y contemplaron diferentes aproximaciones metodológicas. La comparación de los resultados de ambos trabajos se funda en una estrategia de muestreo de "máxima variación", que consiste en la búsqueda de una variabilidad extrema entre unidades de análisis que mantienen entre sí alguna distribución esperada de características (Scribano, 2008). En el caso del artículo, la unidad de análisis en juego son los escenarios laborales de cada investigación y la variabilidad está dada por las formas de empleo: trabajo asalariado en la tienda y trabajo independiente en los emprendimientos. Este contraste principal conlleva a su vez una serie de diferencias relativas al nivel de calificación de los trabajadores (bajo en el caso de las tiendas y alto en los emprendimientos), a la posición social (media-baja en las tiendas y media-alta en los emprendimientos) y el tamaño de las empresas (grande en las tiendas y pequeño en los emprendimientos). El artículo, por tanto, descansa 
en la hipótesis de que este diseño metodológico permite comparar las bifurcaciones de los trabajadores en formas de empleo y trabajo de manera contrastada, y que son representativas del Chile contemporáneo.

En el caso de la tienda por departamento, el estudio se enfocó en los trabajadores de primera línea (es decir, con contacto directo con los clientes), entre 18 y 50 años, contratados directamente por la empresa, con contrato indefinido y en jornada de tiempo completo. El grupo de entrevistados se dividió en partes iguales entre vendedores integrales y trabajadores asociado a un servicio de venta semi-asistida. Los primeros corresponden a cargos con mejor remuneración que se ubican en las áreas en donde la venta requiere un servicio personalizado (calzado, sastrería, electrónica, línea blanca, etc.), en el que los trabajadores se encargan de todo el proceso de venta (desde la captación del cliente hasta el pago en la caja) y cuyo sistema de remuneración se estructura en función de un sueldo base al que se adiciona una comisión por cada venta realizada. El segundo grupo considera tres perfiles de cargo (cajeros, asesores de venta y asistentes) que se encuentran principalmente en las áreas como vestuario o menaje, en las cuales las funciones se relacionan con la organización y el mantenimiento del orden de la sala de venta a fin de garantizar un proceso de compra cercano al autoservicio. En la mayoría de los casos, los trabajadores contaban con la educación media completa y en menor medida, algunos habían realizado o se encontraban realizando estudios en la educación terciaria técnico-profesional.

El trabajo de campo se llevó a cabo entre los años 2014 y 2015, tuvo una duración de cinco meses y consideró tres técnicas de producción de información. En primer lugar, entrevistas semi-dirigidas con trabajadores basadas en un guion que abarcó sus recorridos laborales y ciertas dimensiones de su trabajo (organización del trabajo, las relaciones sociales, expectativas futuras, etc.). En total se realizaron 14 entrevistas divididas en partes iguales según sexo, edad (adulto/joven) y cargo (vendedor/venta asistida) que tuvieron una duración en torno a una hora, las cuales fueron negociadas con los participantes en el lugar de trabajo, pero efectuadas fuera de este. En segundo lugar, entrevistas a informantes clave - a la gerente de tienda y a la encargada de recursos humanos - con la finalidad de conocer el desarrollo que ha tenido la empresa, su modelo de negocios, las políticas e instrumentos de gestión de personas. Finalmente, se llevaron a cabo nueve sesiones de observación no participante en la tienda con el objetivo de aprehender de manera directa cómo se desarrolla el trabajo y que duraron en promedio una hora y media.

En el escenario del emprendimiento social se utilizaron dos técnicas de producción de información. En primer lugar, entrevistas biográficas con 15 emprendedores y asalariados de microempresas enfocadas en la resolución de un problema social en diferentes rubros (educación, salud, vestuario) y pertenecientes a dos ecosistemas 
de innovación social ${ }^{2}$ de Santiago. Las entrevistas cubrieron la mayor variedad de perfiles de empresarios sociales considerando tanto a quienes recién entraban en la vida activa como a quienes contaban con mayor experiencia laboral y comenzaban un nuevo camino profesional. El corpus de entrevistas consideró personas entre los 20 y los 50 años, de los cuales 5 eran mujeres y 10 hombres. Los temas abordados considerar los diferentes caminos recorridos hasta convertirse en emprendedores, los vínculos con los núcleos de socialización como la familia, la educación, el círculo de amigos o personas significativas, principalmente a lo largo de la educación secundaria, educación terciaria y el mundo del trabajo. En segundo lugar, se realizaron 3 entrevistas a informantes claves que consideraron a los directores de los ecosistemas de innovación social y un consultor en emprendimientos sociales vinculado como profesional de apoyo en ambos ecosistemas.

El trabajo de campo tuvo dos etapas llevadas a cabo en febrero y en abril de 2017. El contacto con los entrevistados se realizó mediante los directores de los ecosistemas, los cuales habían previamente participado de las entrevistas exploratorias. A través de ellos accedimos a las bases de datos de correos electrónicos con las cuales pudimos realizar invitaciones personales a los fundadores/as y a los trabajadores/as. Los directores de los ecosistemas tuvieron un rol fundamental en la promoción de la investigación entre los emprendedores, lo cual entregó la oportunidad de acceder a los entrevistados de manera formal y con mayor legitimidad.

Si bien las técnicas de producción de información de cada investigación no fueron precisamente las mismas, en ambos casos buscaron recolectar "datos biográficos". Estos, como recuerdan Dubar y Nicourd (2017), en sí mismos no son suficientes, pues todo depende de la construcción de la mirada sociológica y de las modalidades de su análisis e interpretación. Aunque las investigaciones tuvieron en sus orígenes tanto objetivos ${ }^{3}$ como procedimientos de análisis diferentes, ambas utilizaron como base los procedimientos de codificación axial y selectiva de la Teoría Fundamentada (Strauss y Corbin, 2002). Para este artículo se llevó a cabo un análisis de contenido orientado en los momentos de bifurcación experimentados en cada escenario, poniendo un énfasis especial en los contrastes observados y que fundan el ejercicio comparativo que lo anima.

2. Los ecosistemas son centros en los cuales "germinan" y "florecen" las nuevas empresas, estos son entendidos principalmente como "una red social que se comporta como un sistema biológico, dentro del cual las personas minimizan costos de transacción causados por barreras sociales" (Gatica, Soto y Vela, 2015, p. 15).

3. La investigación sobre el trabajo en la tienda por departamento buscó comprender la formación de las experiencias laborales a partir de la noción de "encrucijada" (Martinic, 2019), mientras que el estudio sobre los emprendimientos sociales abordó el problema de la bifurcación biográfica en sí misma. 


\section{Resultados}

A continuación, se presentan los resultados del artículo los cuales consisten en el análisis de las bifurcaciones laborales en los dos escenarios estudiados: la empresa del retail y los emprendimientos sociales. En ambos casos, la bifurcación es analizada atendiendo a los momentos analíticos del antes y del después del ingreso de las personas al escenario.

\section{La promesa de integración del trabajo en una tienda por departamento}

En el apartado del escenario de la empresa del retail, en un primer tiempo, se analiza el momento previo al ingreso, caracterizado por una adaptación a las escazas alternativas disponibles de las personas; para en segundo tiempo examinar su declinación en la valoración del empleo y del trabajo en la compañía por parte los trabajadores: mientras que el primero es altamente valorado por su estabilidad, el segundo es fuente de insatisfacción debido a la intensidad del trabajo.

\section{El antes: la tienda como una elección adaptada a las oportunidades}

La bifurcación laboral que tiene lugar en los trabajadores del retail se caracteriza menos por la aparición de un evento único que cambia de manera radical sus vidas, que por la afectación de eventos múltiples que desembocan en la inserción en la tienda por departamento. La posibilidad de trabajar en la tienda aparece en los entrevistados como una forma de salir de circunstancias asociada al desempleo, como también a periodos de "inactividad laboral" relacionados al cuidado de los hijos. Estas circunstancias heterogéneas encuentran a los individuos en momentos del ciclo de vida también heterogéneos: dueñas de casa sin experiencia laboral o que interrumpieron su vida laboral para dedicarse al cuidado de los hijos y del hogar; jóvenes que a causa de un embarazo enfrentaron la urgencia de conseguir trabajo, otros que no quisieron trabajar en lo que estudiaron, que congelaron sus estudios o que trabajan para poder estudiar; trabajadores con vasta experiencia en el sector comercio que pasaron por diferentes empresas, algunos también provenientes de rubros distintos y que ingresan - casi la mayoría - por primera vez a una tienda.

Estas situaciones emplazan a las personas en un registro más cercano al padecimiento que al de la agencia, lo que hace que la bifurcación hacia el trabajo en la tienda tome la forma de una preferencia adaptativa, vale decir, un deseo que se adapta a las opciones disponibles (Elster, 2016). Son las oportunidades con las que cuentan los actores lo que da forma a sus deseos - y no al revés -, lo que consecutivamente hace que el trabajo en la tienda no se considere como la alternativa más deseada, sino como la que se tiene a la mano: la más fácil, la menos costosa o la más rápida.

La experiencia de Raquel, una profesora de química que dejó de trabajar para dedicarse al cuidado de sus hijos, es ilustrativa al respecto. Su retorno al trabajo me- 
diante el empleo en la tienda obedeció, antes que a una planificación estudiada, a una casualidad que la encontró en el momento y en el tiempo adecuado.

Yo estaba en mi casa tranquilamente, de dueña de casa, de mamá y mi hija me pidió que... que le buscara por internet una máquina de ejercicio y me puse a mirar los sitios web de los distintos retail y de repente decía "trabaje conmigo", "trabaje con nosotros" o "ingrese su CV". Ingresé mi currículum aquí y en Ripley me acuerdo, y me llamó la atención porque decía media jornada, y como mis hijos ya estaban grandes, menos la más chiquitita que estaba en primero básico y... y ingresé el currículum de pura copuchenta, mi intención no era trabajar, pero sí me llamó la atención de que hubiera media jornada, yo dije "en una de esas, media jornada mañana" [...] no le conté a nadie y a los dos días me llamaron, me llamaron de las dos partes. Yo dije "ya voy a ir", dije yo "a ver qué pasa" porque como a mí, por mi carrera yo nunca pude trabajar porque nunca me ha resultado trabajar en ello porque soy de la generación "que no, porque eres mujer, estás casada", "no, porque tienes hijos", "no, porque esto..., entonces siempre fui, me fui quedando al margen de mi carrera y dije "ya, no voy a trabajar nunca" [...] me llamaron y vine a la entrevista y me llamó la atención [...] así que acepté po. Lo hablé con mi marido, le dije "mira, qué te parece", "ya" me dijo, "ningún problema". Y como yo ya los chiquillos ya estaban grandes ya pasaba la mitad del día sin hacer prácticamente nada en la casa (Vendedora, 53 años).

Su relato ofrece múltiples puntos de reflexión para el análisis de la bifurcación en el caso de las mujeres que son madres. En primer lugar, es característico de las trayectorias laborales femeninas que, producto de la división sexual del trabajo y los modelos de género, se ven interrumpidas por la necesidad de asumir el cuidado de los hijos y el trabajo reproductivo (Guzmán \& Mauro, 2004) y en las cuales el trabajo a tiempo parcial constituye un dispositivo de arbitraje entre trabajo y familia en contextos en donde se ha privilegiado el proyecto familiar (Nicole-Drancourt, 2009). En segundo lugar, el carácter ambiguo de la elección muestra a su vez a qué punto la bifurcación se desencadena a partir de una oportunidad repentina, la cual toma en función de las opciones que pueden desplegarse en el futuro o, en sus palabras, "a ver qué pasa". Por último, ambos puntos pueden asociarse al predominio de los "roles" que les son asignados a Raquel y de su actuación en conformidad a las expectativas de los otros (familia, esposo, quienes le dicen "que no porque eres mujer"), mostrando que la definición de sí misma la hace principalmente en relación a ellos evitando centrarse en ella misma (Zimmermann, 2014). Sin embargo, aunque su relato enfatiza la pregnancia de los roles en su construcción identitaria, el ingreso a trabajar en la tienda revela una toma de posición que permite distanciarse del rol y salir de la inactividad en la que se encontraba. 
En el caso de los hombres, teniendo la misma impronta de una elección circunstancial, la bifurcación se da con un mayor grado de agencia individual. Con una inserción en el mundo del trabajo ininterrumpida por el trabajo reproductivo, lo que marca sus recorridos laborales es la itinerancia entre diferentes tipos de empleo que se asocia a una debilidad de las identidades de oficio previas al ingreso a la tienda. En efecto, el tránsito por rubros diversos, en empleos tanto formales como informales, marcha a contrapelo de la cristalización de identidades basadas en el saber-hacer, en el deber-ser y en un sentido de pertenencia (Stecher \& Soto Roy, 2019). El recorrido de Juan, vendedor del departamento de electrónica, es decidor al respecto.

Llegué por casualidad en realidad, yo trabajaba en discoteques y ese era como mi fuerte y trabajé mucho tiempo en discoteques. Administré varias discotecas y llegó un momento en que dije "no, no quiero más de esto, no quiero más noche" [...]y tocó justo cuando estaba en Valparaíso, estaba administrando una discoteque en Valparaíso y vivía allá, llevaba un año viviendo allá, y hubo justo un problema con mi hija, ¿ya?, tengo una hija y hubo un problemita y yo estaba como león enjaulado porque no podía venirme para acá, cachai, entonces dije "no, hasta aquí llegué". [...] El 2010 me parece que entré a HP, que ahí es donde yo entré al retail. [...] Después de eso tuve un problema con el gerente de la agencia que es de HP, y tuve que irme de HP y en todo este tiempo que estuve trabajando con HP conocí al jefe de acá, que era vendedor de Falabella Oeste. [...] Entonces me dijo "vente para acá, para que vas a estar sin pega", porque [...] venía diciembre, es una época donde trabajar en mall: las lucas llueven. O sea, no trabajar en esa época es de gil (Vendedor, 38 años).

En el testimonio de Juan se logra ver el lugar de la agencia individual mencionado: el "administraba" discotecas, decidió llegar "hasta ahí" y luego "entra" al retail. Sin embargo, producto de un imprevisto familiar deja la actividad que había desarrollado por más tiempo, reconvirtiéndose en un asalariado luego de ser independiente. $\mathrm{Su}$ llegada a la tienda aquí estudiada ocurre luego de un periodo de cesantía y revela un aspecto presente en varias entrevistas, este es, el hecho de contar con un contacto que le permite el ingreso. Pero como él lo señala, su decisión se ve sobre todo gatillada por las ganancias que, en tanto vendedor comisionista, el trabajo le permitirá obtener.

Lo que evidencia el análisis de las entrevistas es que el ingreso a la tienda no es precisamente una estrategia premeditada y selectiva de búsqueda de trabajo para conseguir progresivamente mejores condiciones de vida. La preferencia adaptativa, marcada por el carácter contingente de la oportunidad de ingresar a la tienda, encuentra así un eco en la lógica del "arreglárselas", bajo la cual las personas tomarían un trabajo "porque necesitan el dinero para salir del paso, encontrar algo que hacer, a alguien con quien hablar o hacer nuevos amigos" (Spink, 2011, p. 9). Cualquiera sea el 
caso, no obstante, el trabajo en la tienda constituye una oferta de empleo poco usual para lo que ha sido la tónica de los recorridos laborales.

El después: el declive de la promesa de la integración frente a la intensificación del trabajo

En el corazón de esta bifurcación se encuentra el proceso de conversión de estas trayectorias laborales caracterizadas por su discontinuidad y pluriactividad, así como la predominancia de preferencias adaptativas, en una experiencia de trabajo asalariado con contrato indefinido que otorga acceso a garantías sociales, con un salario mensual y oportunidades de desarrollo de carrera. Dicho de otra manera: el ingreso a la empresa "homogeniza en un estatuto común de empleo" la diversidad de los recorridos, operando como un "clivaje entre las experiencias laborales anteriores y un modo de inserción asalariada, de mayor estabilidad, que crea o refuerza en un colectivo diverso de trabajadores el rol e identidad de empleados de grandes empresas del sector comercio" (Martinic \& Stecher, 2020, pp. 12-13).

Esta homogenización de los recorridos biográficos va de la mano con una oferta de integración que funciona de las cuatro maneras que analizan Martinic y Stecher (2020): estatutaria, relacional, formativa y promocional. En términos más generales, esta integración equivale a un proceso de socialización profesional que implica la adopción de un oficio, de un conjunto de conocimientos y del saber-hacer de la venta, así como la incorporación a un colectivo de trabajo y a una empresa que busca que los trabajadores hagan propios sus fines. Esto último, una modalidad de control ideológico propio de la gestión neomanagerial, permite entender que la integración es también una manera de socializar a los trabajadores en los valores de la empresa alineados con su estrategia comercial. En breve, la integración también conlleva una dosis de dominación.

[La empresa] tiene un ADN que habla de ciertas características que es el servicio, que es el trabajo en equipo, que es la honestidad, y una serie de competencias y de características que busca en sus trabajadores (Encargada RRHH, 29 años).

La incorporación de este ADN - el desenvolvimiento en el trabajo de acuerdo a los valores corporativos - es la llave de acceso a la promoción interna y al desarrollo de carrera en la empresa. El lugar de las jefaturas de la tienda en la dimensión promocional de la integración posee una gran importancia. En efecto, la recurrencia en las entrevistas de las historias de los superiores que han entrado como vendedores y han terminado siendo jefes, constituyen a la vez el testimonio de que las posibilidades de evolución de la empresa y el modelo a seguir de quienes vienen de incorporarse. Sus testimonios abren el horizonte de expectativas profesionales de los trabajadores. 
Acá el jefe me dijo, "mira, acá está la opción”, me dijo, "tú podí entrar, no sé po, haciendo aseo ahí en [la empresa] y podí terminar como yo... y eso no va a hacer en un lapso de diez años, sí en un año o dos años lo hiciste bien, te evalúan acá y..." [...] él entró trabajando de asistente de probador... él estaba parado todo el día esperando que los huevones entraran y que no te robaran ropa y ahora es el gerente general de [esta tienda], pero así empezó (Eugenio, asistente de venta, 28 años).

Es justamente esta "promesa" de evolucionar en la empresa lo que se pone a prueba en los recorridos laborales de los trabajadores luego de la bifurcación. Aunque significativa como oferta de reconocimiento de las cualidades profesionales para quienes no han solido ser reconocidos en el trabajo, la promesa de carrera pierde muchas veces su atractivo a la luz de diferentes aspectos del trabajo como su intensidad, sus horarios atípicos y las exigencias temporales o la frustración por no ascender. Las declinaciones de esta promesa se dan de manera diferente entre jóvenes y adultos, así como entre hombres y mujeres.

En los más jóvenes, la bifurcación significó una verdadera paradoja en la construcción de sus proyectos de vida, pues si el ingreso en la tienda estuvo asociado al acceso a mejores condiciones de vida, al mismo tiempo generó expectativas de autorrealización que el trabajo y las posibilidades de crecer ya no parecen satisfacer. Aquello da lugar a una experiencia ambivalente, como se aprecia en el siguiente testimonio, en donde pese a la identificación con la organización y el gusto por el trabajo, no existe una proyección en la empresa.

[Estoy] totalmente identificado y me gusta trabajar acá. Si no fuera por la poca gente que entra [...] como cliente que me afecta el bolsillo y fueran mejores mis lucas, sería una empresa perfecta. Tampoco quiero quedarme aquí [...] yo quiero estudiar, como te digo, estudié dos veces, ni una de las dos estoy ejerciendo, ni mecánico, ni pintor de auto fui, ni gastronomía, ¿cachai?

\section{Y, ¿qué te gustaría estudiar?}

Eh, no sé, te lo juro que no sé. Mi papá me, [...] me exige mucho en ese sentido, quiere que yo estudie, no, no sé, no quiero mandarme el cagazo de nuevo, pagué dos años, cachai, que no hice nada, no quiero hacerlo de nuevo. (Manuel, vendedor, 24 años).

El trabajo en la empresa comienza a concebirse como una opción deslucida en relación a los estudios en la educación superior, pero la decisión de renunciar a la empresa no siempre es instantánea y en ocasiones ocurre que los jóvenes perduran en un estado liminal, en un empleo que se concibe tan circunstancial como permanente (Martinic, 2019), que es similar a la figura del futuro de ensueño (Soto et al., 2021). El 
hecho de tener otros planes fuera del retail, no obstante, es una de las ventajas propias de la edad. La opción del exit, según la fórmula de Hirschman (1970), no corre para los más adultos pues saben que la edad (como la calificación) es un atributo que el mercado laboral castiga. Pero, a la vez, el ascenso en ocasiones tampoco es una opción, como en el caso de Raquel, para quien ser jefa exige una disponibilidad temporal incompatible con la vida familiar.

Yo tengo hartos años en ese departamento entonces sé el tejemaneje entero y todo el mundo me ha preguntado a mí por qué no soy jefe y, ¿sabí por qué no? Por el horario de ellos. Ellos trabajan mucho y tienen que estar $24 / 7$ pendientes de la tienda, [...] si hay un problema y nadie lo puede solucionar él tiene que venir, en su contrato tiene que decir que él está dispuesto a venir a solucionar el problema [...] y yo con cuatro hijos, una familia, mamá y papá, no... prefiero quedarme ahí donde estoy (vendedora, 53 años).

El rechazo a ascender es consecuencia de una toma de consciencia tanto de la sobre exigencia temporal que implica ser jefe, como de sus costos familiares. Así, si la continuación puede entrañar cierta lealtad hacia la empresa, se trata más bien de mantener un equilibrio entre, por un lado, la imposibilidad del exit y, por otro, del desborde temporal del ascenso. El peso del arbitraje entre familia y trabajo, no obstante, no es igual entre mujeres y hombres, pues si las primeras logran apenas separar estas esferas de sus vidas, los hombres hacen una partición mucho más neta entre ambas.

Esto último es el caso de Alberto, un jefe de venta de 63 años con más de 20 años en la empresa para quien el trabajo ha sido una forma de que sus hijos "obtuvieran buena educación", pero que reconoce haberse saltado "algunas etapas de los niños", porque "yo trato de no mezclar nunca las cosas: la casa ni el trabajo". No obstante, su involucramiento en el trabajo si bien le permitió ascender, no lo hizo en la misma medida que él hubiese esperado, lo que dio lugar a una experiencia de frustración:

Una postulación está abierta en el canal de [la empresa], entonces dice "se necesita gerente para tal", entonces [uno] postula, y hay veces que no hubo postulación. [...] y apareció una gerenta que uno dice "chuta, ¿de a dónde salió esa gerenta?". [...] Queda la nebulosa porque esa persona estuvo a punto de ser despedida y se le dio la posibilidad de llegar a otro cargo más arriba, en circunstancia que hay veinte con mayores posibilidades que esa persona, que nunca han tenido un problema. Y eso no es básicamente por mí, ¿ah?, o sea, porque, yo te digo, no es prioridad, si se da se da y yo se lo dije a la gerenta "se da, se da, jefa, si yo estoy súper bien aquí". Pero hay otras personas que sí, que son jóvenes que en estos momentos van hacia arriba, que a lo mejor la frustración va a ser muy grande. 


\section{Pero, ¿usted se sintió frustrado en algún momento?}

Varias veces de mi vida me sentí frustrado en [la empresa].

Así, la integración, particularmente en su veta promocional, no resiste bien la prueba del tiempo en la tienda, observándose importantes declinaciones según edad y género de los entrevistados. Lo que parece común en estos recorridos, pese a ciertas diferencias de grados, sin embargo, es la prevalencia de un vínculo al empleo por sobre el vínculo al trabajo en la bifurcación. En cierto modo, las múltiples formas de integración del empleo en la empresa son más valoradas que el exigente trabajo en la tienda, lo que contribuye a entender que los trabajadores continúen en la empresa pese a todo.

\section{La creación de empresas de innovación social como bifurcación laboral}

En el caso de los emprendimientos de innovación social se observa, en un primer momento, que la creación de la empresa puede ser entendida como el resultado de un proceso de desidentificación de las personas respecto al proyecto profesional hasta ese punto desarrollado. Luego, en un segundo momento, se examina el modo en que el emprendimiento emerge como una forma de reorientar y revalorizar la trayectoria profesional de los individuos, lo cual implica el desafío de sincronizar los diferentes ámbitos de sus vidas.

\section{El antes: el proceso de desidentificación}

Entendemos la creación de un emprendimiento de innovación social como una bifurcación en tanto representa un camino profesional inesperado, en el cual emerge la oportunidad de acercar los valores personales a los objetivos profesionales mediante la orientación de la carrera. Diversas circunstancias llevan a las personas a lanzarse en este proyecto: la incertidumbre de la primera inserción laboral, las pocas posibilidades de crecer profesionalmente en el lugar de trabajo, periodos de inactividad prolongados o las ganas de cambiar de rubro, dedicarse a algo que genere ingresos y que ayude a los demás. Los momentos del ciclo de vida son igualmente heterogéneos: jóvenes terminando estudios universitarios y que no se proyectan en sus respectivos campos, trabajadores con varios años de experiencia laboral que deciden cambiar de rumbo o personas que ven una opción de manejar mejor sus tiempos y tener mayor autonomía. Los relatos de los emprendedores dan cuenta de una inserción basada en decisiones y planificación, es decir, en una alta capacidad de agencia. Sin embargo, al entrar en detalle en el proceso de ruptura, vemos que el camino es bastante más turbulento, muy dependiente de los apoyos que se tienen (materiales y emocionales) y con altos costos en cuanto a la organización de la vida cotidiana. 
El origen de la idea desde la cual nacen las empresas sociales está ligado a circunstancias heterogéneas. Para que ésta tome forma de oportunidad comercial, diversos acontecimientos y elementos se cruzan. La idea de negocio no nace como tal, ella evoluciona de forma progresiva y encuentra sus orígenes en la evaluación de una experiencia vivida por los emprendedores, ya sea como clientes, como estudiantes o como asalariados en una empresa. Sin embargo, no hay una causa previa que dirija el proyecto emprendedor hacia el nicho "prosocial".

El proyecto nace hace más tiempo atrás a raíz de una enfermedad de mi hija [...] no tenía el interés social, sino que fue que tenía algo, ayudó a mi hija, traje una tecnología, la desarrollamos acá para mi hija, pero empezamos al tiempo después dije "chuta, esta cuestión podría comercializarse" (Hugo, ingeniero, 48 años).

El giro hacia lo social, aparece como una apuesta en un ámbito de negocios que podría ampliar las posibilidades de éxito del proyecto. No obstante, a medida que los individuos exploran el medio del emprendimiento social, las evaluaciones que dieron origen a sus ideas de negocio comienzan a convertirse en verdaderas críticas, ya sea de un servicio, un producto o un medio económico en el que se desea participar. Es en este momento de los relatos cuando el interés comercial se cruza con argumentos de carácter moral en los cuales se cuestiona el sentido del trabajo y el propósito por el cual encauzar la actividad laboral. Vemos entonces que las personas que emprenden en este nicho pasan por procesos de construcción de sentido y otorgamiento de sentido a los problemas sociales que identifican. Asimismo, generan un diálogo interno en cuanto al sentido del trabajo, cruzado con criterios de justicia social, que permea la construcción de la propia actividad (Kimmitt y Muñoz, 2018).

La bifurcación tiene una declinación diferente según el momento del ciclo de vida de los entrevistados. En el caso de los más jóvenes, el proceso de ruptura se da al momento de la primera inserción laboral cuando, al finalizar la universidad, se dan cuenta de que no les motiva trabajar en lo que estudiaron, lo que puede entenderse como un proceso de desidentificación en relación a la carrera estudiada, ya sea por el tipo de trabajo, el campo laboral o por las bajas tasas de empleabilidad. Este periodo de desencantamiento profesional instala la idea de generar un emprendimiento vinculado a la carrera estudiada, pero en un ámbito laboral diferente. Por ello, la creación de la propia actividad puede entenderse como una forma de hacer frente a la primera inserción, generando una ocupación que les entregará mayor certeza en cuanto al trabajo, pero especialmente por su componente prosocial, como un modo de hacer converger los intereses personales con la experiencia profesional. Ante la incertidumbre del futuro laboral, el emprender es un intento por orientar lo que se va a aprender y las habilidades que se quieren desarrollar. 
Yo creo que eso fue al final de la universidad, cuando yo estaba al borde de un risco, para decirlo gráficamente (risas), y no tenía idea si tenía que saltar, construir un puente o quedarme donde estaba. Entre todas mis opciones tenía la sensación de que esta alternativa podía generar un impacto mayor en mi vida a nivel profesional y personal. (Ignacio, bioquímico, 26 años).

En el caso de los adultos, la bifurcación aparece como una respuesta al estancamiento de sus carreras debido a la imposibilidad de seguir desarrollándose profesionalmente en su lugar de trabajo. Estas circunstancias gatillan también un proceso de desidentificación en el cual los trabajadores se distancian del proyecto laboral en curso. La expectativa de desarrollo profesional pierde su sentido, incluso a pesar de tener cargos directivos y diversos beneficios de la empresa. La orientación de la bifurcación se dirige a la búsqueda de formas de revalorización de las capacidades desarrolladas y de reactivación de la carrera. Este "salto evolutivo", como lo denomina Hugo, se materializa en la creación de un emprendimiento que encarna un nuevo comienzo, acorde a nuevos intereses profesionales y personales.

Fue un tema en que tú te vai dando cuenta en que tu podís hacer más cosas de las que estai haciendo, que tus capacidades pueden llegar a otro estado o la organización donde tu trabajai no te aguanta hacer este tipo de cosas [...] ahí tu decis "bueno, la empresa se condice o no se condice”, el lavado de imagen, yo quería hacer algo más entretenido (Ingeniero, 48 años).

Un aspecto transversal tanto en los más jóvenes como en los más adultos es que los dilemas que activan las bifurcaciones se presentan vinculados al sentido que se le quiere dar a la actividad. En otras palabras, la creación de este tipo de empresas representa una alternativa que permite reformular los objetivos profesionales y en la cual el "ganar dinero ayudando" constituye el eje de su narrativa. Así lo denota el caso de Vicente, para quien el encuentro con sus primeros clientes le permitió reformular las motivaciones y el sentido de su trabajo:

Llegamos a esta casa y estaba la guagüita, los dos cabros, estaba la mamá o la nana, [...] y yo toda la vida he trabajado en informática, creo que es para lo que nací, pero nunca se había dado una conexión como la que sentí ese día, o sea, yo no le estaba instalando un software, no les estaba enseñando a ocupar un programa, les estaba cambiando la vida y, pucha, claro, nos invitaron a comer con ellos, tenía la guagua en brazos mientras trabajaba, nos dieron comida, y fue bacán, y yo salí y de verdad "esto es lo que yo quiero hacer toda mi vida”... hasta antes de eso yo no tenía, o sea, yo sabía que me gustaba ayudar, y ayudaba con mi trabajo, pero no sabía que era un emprendedor social. Y ahora al que me pregunta, eso es lo que soy (Informático, 37 años). 
Para Vicente, este acontecimiento fue vivido como una verdadera reconversión. El cambio de visión y de motivaciones con el trabajo gatillaron cambios duraderos en su identidad debido a la cercanía que sintió con sus primeros clientes, con su contexto de vida, sus aspiraciones y sus historias como comerciantes. Como un continuo al proceso de desidentificación ejemplificado en los extractos anteriores, la bifurcación genera espacios para cambiar la propia identidad profesional. El trabajo identitario en este caso es realizado en base a criterios relacionales y vínculos de intimidad con otros (Knox et al., 2021).

El después: desincronización de la vida cotidiana y orientación de la experiencia laboral

Los relatos de vida de los emprendedores muestran un cambio importante en la articulación de la vida cotidiana. El equilibrio de la secuencia biográfica se ve especialmente afectado ya que la dinámica entre las esferas pública y privada forma parte activa del proyecto profesional (Ferreras, 2007). Así lo denota uno de los entrevistados, el cual comenta: "Es un cambio de mentalidad que se produce al cabo de unos años, cuando te das cuenta de que en realidad estás corriendo una maratón" (Roberto, biotecnólogo, 25 años).

Los emprendedores expresan una desincronización radical de su vida cotidiana. Incertidumbre e inestabilidad emocional son los principales adjetivos utilizados para describir el momento de embarcarse en la aventura empresarial. Los emprendedores se involucran tanto en el proyecto que los límites entre el trabajo y la vida privada desaparecen. La situación de Hugo nos revela que el emprendimiento no es en ningún caso un proyecto solitario. La viabilidad de este se sostiene en las redes de apoyo que se tengan y de la capacidad de articularlas. En su relato, comenta cómo tuvo que recurrir a sus familiares y contactos para buscar apoyo. Cuando decidió crear su propia empresa, la articulación entre la esfera privada y pública fue el primer paso:

Tuve que pedir ayuda en los colegios de mis hijos, que me subvencionaran con becas, empezar a saber pedir ayuda po, yo nunca pedía ayuda, siempre pagaba todo cash, pagaba el año completo de los colegios. Tuve que saber transparentar mi situación, que no es menor, explicar todo, decir que necesitaba una beca para mis hijos, ya no podía pagar los colegios completos. Hablé con mi papá, empezar a pedir ayuda bastante, obviamente el apoyo de mi señora, sino esto no resulta [...] Tengo que vender algo, empezai a buscar socios, a hacer alianzas con otras empresas que venden lo mío y yo lo de ellos, buscar sinergias, técnicos, todo, armar algo que te permita tener una cierta estabilidad y obviamente que te altera todo..." (Hugo, ingeniero, 48 años). 
El entrevistado nos relata cómo se va tejiendo en la práctica su proyecto biográfico-laboral, lo que él desea para el futuro, lo que es realizable y alcanzable en función de los objetivos laborales que se fijó como emprendedor. Hugo no solamente tuvo que pedir ayudas financieras, sino que orquestó un alineamiento de su esfera pública y privada, buscando apoyos materiales y soportes emocionales que le permitieran sortear esta aventura con un mínimo de certidumbre. El extracto da cuenta también de los movimientos más prácticos como vender cosas para costear gastos del hogar, la activación de su capital social y los intentos por acrecentarlo, generando alianzas con otros emprendimientos. Todo lo anterior con miras a estabilizar tanto el nuevo proyecto laboral en curso como también los aspectos vinculados al ámbito de la familia y la economía del hogar.

Este mismo movimiento de desincronización de la vida cotidiana resulta notoriamente diferente en el caso de las mujeres, pues la articulación entre el trabajo y la familia se transforma en una de las principales tensiones al momento de comenzar a construir la nueva organización (Naranjo, 2014). En el caso de Valentina, la crianza de los hijos fue muy difícil de gestionar cuando ella y su marido se convirtieron en emprendedores. Ella era la encargada de las labores de cuidado y crianza y, en consecuencia, la principal responsable de articular ambos ámbitos:

Como que tratamos de coordinarnos y... igual las decisiones como que terminan pasando por mí po' los permisos, igual tengo un hijo adolescente po', que no es fácil también [...] me tocó un período difícil entre la adolescencia de mi hijo y empezar a vivir este mundo del emprendimiento. Fue todo, se me mezcló también [...] sentía que no lo podía dejar solo, más peleas también obviamente que se producen entre la mamá y el hijo, que mi hijo quiere tal cosa, la mamá no le da, ¿cómo llevai a cabo que el cabro no se desvíe?, ¿cachai?" (Profesora, 34 años).

Para las mujeres, estas tensiones entre diferentes esferas suelen tener efectos en la trayectoria laboral y vital (Undurraga, 2013). En el caso de Valentina, el peso de la articulación del trabajo y la familia recae exclusivamente en ella y es narrado como un rol irreversible. El "tratar" de coordinarse con su pareja, pero que finalmente "igual las decisiones terminan pasando por mí” deja entrever la prevalencia de la lógica del rol que asigna la responsabilidad de cuidado exclusivamente a la mujer y que afecta el modo de vinculación al trabajo.

En el caso de Vania, el intento de articulación de las otras áreas de la vida, la llevan a jugar diferentes roles que, en ocasiones, resultan contradictorios entre sí. Múltiples identidades coexisten incluso en el transcurso de un solo día. Asimismo, el "desequilibrio" entre las esferas de su vida es experimentado de manera individual y atribuida a la falta de organización personal: 
Balanceo pésimo porque de alguna manera estaba tan enganchada con $\mathrm{mi}$ trabajo, era tal el compromiso que no podía desconectarme del teléfono o del correo, era más por la conexión que tenía con el proyecto y esa etapa fue difícil para mí establecer fronteras. [...] La parte buena es que soy consciente y la parte mala es como que me pasa que salgo de la oficina y no alcanzo a desconectarme y ya estoy con mi hija y dos amigos en el auto yendo a no sé dónde, esa cosa como de cambiar de un rol a otro tan distintos entre sí [...] entonces llego a la casa y me doy cuenta de que sí tengo un cierto desequilibrio en mi vida y de que llegan las nueve de la noche y no doy más [...] es como un caos, entonces creo que me gustaría poder mejorar algunas cosas pero bueno, me relajo porque no se puede tener todo, me gusta lo que hago y tal vez son etapas en que uno pone más esfuerzo en algunas cosas (Comunicación y marketing, 31 años).

Debido a los desequilibrios, el proyecto profesional se convierte en una prioridad, lo cual sirve a su vez para justificar los sacrificios más o menos voluntarios de la vida privada. Ya sea para reforzar el proyecto o para satisfacer necesidades materiales, las esferas privada y pública se mezclan por completo. Como acabamos de revisar, esto varía considerablemente según el género de los entrevistados. En el caso de las mujeres emprendedoras, sobre todo cuando hay hijos, el desajuste se relaciona con la multiplicidad de roles que deben adoptar en función de las actividades del día, y la dificultad para conciliar el emprendimiento con el trabajo doméstico. Los dilemas de las mujeres emprendedoras reflejan un tiempo sexuado de la actividad, el cual se funda en una temporalidad basada en la disponibilidad al otro y el sentido de anticipación (Bessin \& Gaudart, 2009). Por el contrario, en los hombres, se observa una mayor movilización de recursos entre esferas (apoyos materiales y emocionales). Además, los relatos sobre lo que tuvieron que sacrificar tienen que ver más bien con el tiempo de ocio, sus amistades y otras actividades extralaborales, lo cual presentan como algo voluntario o "elegido".

El emprendimiento de innovación social constituye, en cierta medida, una forma de crítica a las trayectorias laborales disponibles y a los estilos de vida que se les asocian. En el ámbito del trabajo, las bifurcaciones de los emprendedores sociales reflejan una búsqueda de control de la experiencia profesional, al mismo tiempo que un intento por orientar el proyecto laboral:

Para mí fue $100 \%$ profesional, como profesional en el sentido de que yo quería probar suerte con esta empresa, suerte en el sentido de probar que el proyecto funcionara ¿cachai?, por eso es sin duda mucho más personal, pero yo quería que mi desarrollo profesional estuviera por ahí [...] (Ignacio, bioquímico, 26 años). 
Los recorridos laborales de los emprendedores apuntan a una forma de orientación o gestión de los desafíos que aparecen en el mundo del trabajo, de manera tal que puedan adquirir conocimientos y aprendizajes que consideren más "coherentes" y "apasionantes". Esta búsqueda de sentido y de orientación de la experiencia profesional, encarna una forma de crítica artista mediante la cual se ponen en tela de juicio los valores y opciones básicas de las trayectorias laborales tradicionales. Esta crítica, según Boltanski y Chiapello (2002), se caracteriza por un rechazo al desencanto que resulta de dos procesos inherentes al capitalismo: la mercantilización y la racionalización, con lo cual el emprendimiento social representaría una forma de interrumpir este modelo y buscar una salida alternativa. Esta crítica es modulada por los ecosistemas de innovación social y actúa como justificación del vuelco de los emprendimientos hacia el nicho económico prosocial.

Para mí sería mucho más fácil irme al almacén [ríe] y quedarme ahí, ¿cachai? [...] de verdad podría ganar plata, podría estar como tranquila, sentir como que al final hoy día como que cuento con una plata segura, ¿cachai? Mi pareja podría trabajar en una empresa, y ganar bien; su área hoy día da pa' ganar más lucas, ¿cachai? O sea, hoy día, si la vida fuera tomarla, así como, más simple, chao con esto (Valentina, profesora, 34 años).

La búsqueda de control de la trayectoria laboral a través de la creación de la propia actividad, es un intento de orientación de la carrera que enfatiza la individualización del proyecto profesional a través de la reformulación del sentido del trabajo. La crítica a las trayectorias laborales disponibles lleva a los emprendedores sociales a evaluar sus posibilidades y apoyarse principalmente en sus recursos individuales como el capital social y cultural. Dado que el emprendimiento es un proyecto laboral de alta incertidumbre, las redes de apoyos personales y los nuevos contactos que puedan generar constituyen el principal recurso para estabilizar la nueva posición profesional. La apuesta revela, sin embargo, la valoración del vínculo al trabajo por sobre el vínculo al empleo, en la medida en que se está dispuesto a sacrificar la estabilidad y seguridad que brinda ser asalariado, priorizando la realización en el trabajo y el desarrollo de aprendizajes que se quieren tener como profesional.

\section{Conclusiones}

Las principales conclusiones a las cuales este ejercicio comparativo nos permitió llegar son cinco. En primer lugar, en el momento del antes se observa, en ambos casos el peso determinante tanto de los recorridos laborales como de la posición social y del conjunto de recursos y soportes con los que cuentan los individuos al momento de enfrentar la bifurcación y que se asocian a grados desiguales de agencia. Mientras que en el escenario de la tienda se observa como en personas de bajo nivel de calificación 
y procedente de sectores medios y populares prima una capacidad agencia limitada a preferencias adaptativas relacionadas con alternativas muy circunstanciales, en los emprendimientos sociales se constata un grado mayor de agencia que, gracias a capitales educacionales, económicos y sociales, permite "crear" una alternativa profesional para salir de situaciones de estancamiento profesional y de las limitaciones del mercado laboral. La capacidad de actuar en la bifurcación biográfica, en ese sentido, se encuentra íntimamente ligada a la distribución desigual de recursos y de oportunidades que brinda el entorno de los individuos (Zimmermann, 2014).

En segundo lugar, en estrecha vinculación con lo anterior, los momentos del antes y el después de las bifurcaciones laborales hacen posible constatar la asimetría de los vínculos al trabajo y al empleo. Aquello, que constituye la principal conclusión de nuestro estudio, puede formularse esquemáticamente de la siguiente manera: si en el retail el vínculo a la protección y a seguridad que brinda el empleo prevalece por sobre el vínculo al trabajo, en los emprendimientos sociales el vínculo al trabajo se valoriza al punto de abandonar un vínculo al empleo estable. La entrada en el mundo laboral del retail en muchos casos no es el resultado de una búsqueda intencional de empleo orientada por un deseo de realización y satisfacción en el trabajo. El trabajo aquí está orientado principalmente al mejoramiento de la calidad de vida, al aumento de los ingresos o a la posibilidad de realizar otros proyectos como estudiar en la universidad: en otras palabras, se trabaja para lograr otros objetivos que no están necesariamente vinculado al oficio que se realiza ni a las opciones de carrera que otorga la organización. El emprendimiento, por su parte, refleja justamente el movimiento contrario. Representa una forma de acortar la brecha entre intereses personales y laborales: el emprendimiento social otorga mayor coherencia a los desafíos profesionales que se enfrentan y a los aprendizajes que se desean obtener. Mediante una visión crítica de la situación laboral de asalariado y las posibilidades futuras, el emprendimiento refleja un intento por orientar la experiencia profesional hacia los desafíos y aprendizajes que los actores consideran más significativos. El dilema que activa la bifurcación tiene relación con el sentido que se le quiere dar al trabajo y que se resuelve dejando a un lado la seguridad del empleo en una empresa. Las bifurcaciones estudiadas dan cuenta de modos de inserción laboral que se asemejan- en el primer caso - a la integración laboriosa y - en el segundo caso - a la integración incierta analizadas por Paugam (2007).

En tercer lugar, el tema del reconocimiento emerge como un elemento central en las experiencias laborales analizadas. En el caso del retail, el reconocimiento está vinculado al hecho de integrarse en una red laboral de pares y superiores valorados por los mismos trabajadores. En el caso del emprendimiento, si bien existe también un proceso de integración a una nueva red de personas, básicamente en las redes del medio del emprendimiento social, el reconocimiento se relaciona con los logros de 
la empresa y en última instancia de su líder, es decir, es un reconocimiento del desempeño de la nueva empresa materializado en su líder y sus propuestas innovadoras.

En cuarto lugar, ambas bifurcaciones constatan un importante nivel de inconformidad por parte de los trabajadores en relación a las condiciones laborales. Ya sea a causa de los bajos ingresos que caracterizan al país (Durán y Kremerman, 2014), las escasas oportunidades de desarrollo profesional en las empresas (Ramos, 2009) o el rechazo al contenido mismo del trabajo, lo cierto es que las bifurcaciones son en parte gatilladas por el desajuste entre las expectativas (laborales, aunque no únicamente) y las condiciones objetivas, las que muchas veces continúan en el nuevo escenario al cual se ingresa. Entre las innegables conquistas del desarrollo socioeconómico en Chile, pervive en los individuos una insatisfacción que en el caso del retail se expresa en los anhelos depositados en la educación superior mientras que en los emprendimientos sociales el malestar es uno de los elementos centrales para dar arranque a los nuevos proyectos.

Por último, la dimensión de género nos permite ver que las prácticas temporales como la sincronización de las esferas de la vida se desarrollan, en el caso de la mujer, en función de la relación y disponibilidad al otro (Bessin \& Gaudart, 2009). Igualmente, los resultados dan cuenta de una coexistencia de múltiples identidades que se despliegan según la experiencia de trabajo, sus significados y la etapa vital en la que se encuentran las personas (Undurraga y Abarca, 2021). En los hombres, existe un intercambio más fluido entre la esfera del trabajo y la familia, materializado en forma de "apoyos" económicos y emocionales durante la creación de la empresa. Finalmente, aparece como algo transversal a ambos escenarios el relato de cómo las mujeres terminan confrontando diferentes roles de género en sus inserciones laborales. No así los hombres, quienes tienen mayor autonomía en la construcción del proyecto laboral. La situación de las mujeres expresa la dificultad de hacer carrera conjugando diferentes roles sociales (Zimmermann, 2014).

El análisis de la comparación de las bifurcaciones biográficas en dos escenarios laborales permite constatar los potenciales aportes de la sociología del curso de vida al campo de los estudios del trabajo en América Latina. Estos, como lo evidencia nuestro análisis, se relacionan con el énfasis otorgado al desarrollo en el tiempo de la toma decisiones, de la reflexividad socialmente situada y de la gestión de las diferentes esferas de la vida en los recorridos laborales. Aunque estos elementos no son propiedad únicamente del enfoque del curso de vida, sí podríamos creer que la mirada diacrónica de los eventos biográficos, el foco en las circunstancias y en los eventos individuales, pero sobre todo en la temporalidad de estos, lo distinguen de otras aproximaciones. Al mismo tiempo, la noción de bifurcación biográfica contribuye a recalibrar la importancia otorgada a los eventos imprevisibles y determinantes que, por el hecho de ser específicos o poco frecuentes, suelen ser pasados por alto en las 
ciencias sociales. El artículo, en ese sentido, problematizó un evento común, pero con múltiples declinaciones en dos categorías diferentes de trabajadores, restituyendo la importancia que tuvo en las biografías individuales.

\section{Referencias}

Abramo, Lais (2004). ¿Inserción laboral de las mujeres en América Latina: una fuerza de trabajo secundaria? Revista Estudios Feministas, 12 (2): 224-235.

Austin, James, Howard Stevenson \& Jane Wei-Skillern (2006). Social and Commercial Entrepreneurship: Same, Different, or Both? Entrepreneurship Theory and Practice, 30(1):1-22. https://doi.org/10.1111/j.1540-6520.2006.00107.x.

Bargsted, Mariana (2013). El emprendimiento social desde una mirada psicosocial. Revista Civilizar Ciencias Sociales y Humanas, 13(25): 121-132.

Barthe, Jean-Francois, Nathalie Chauvac \& Michel Grossetti (2016). Entrepreneurs de circonstance : une enquête sociologique sur les fondateurs de start-up en France. Revue de l'Entrepreneuriat, 3(3-4): 163-180. https://doi.org/10.3917/entre.153.0163.

Bell, Robin, Peng Liu, Huirong Zhan, David Bozward, Jing Fan, Helen Watts \& Xiaoyu Ma (2019). Exploring entrepreneurial roles and identity in the United Kingdom and China. The International Journal of Entrepreneurship and Innovation, 20 (1): 39-49. https://doi.org/10.1177/1465750318792510.

Bessin, Marc, Claire Bidart \& Michel Grossetti (2009). Bifurcations : Les sciences sociales face aux ruptures et à lévénement. Paris : La Découverte.

Bessin, Marc. et Gaudart, Corinne. (2009). Les temps sexués de l'activité : la temporalité au principe du genre? Temporalités [En ligne], 9 | 2009, mis en ligne le 30 septembre 2009.

Bidart, Claire (2006). Crises, décisions et temporalités : autour des bifurcations biographiques. Cahier internationaux de sociologie, 1 (120): 29-57.

Boltanski, Luc y Eve Chiapello (2002). El nuevo espíritu del capitalismo. Akal, tres cantos, España.

Bueno Castellanos, Carmen (Coord.) (2020). Ser emprendedor en el México del siglo XXI. Universidad Autónoma del Estado de México y Universidad Iberoamericana, Ciudad de México.

Calderón, Álvaro (2006). El modelo de expansión de las grandes cadenas minoristas en Chile. Revista de la Cepal, 90, 151-170.

Cárdenas, Ana, Felipe Link \& Joe Stillerman (2012). ¿Qué significa el trabajo hoy? Cambios y continuidades en una sociedad global. Santiago: Catalonia. 
D’Epinay, Christian-Lalive, Jean-Francois Bickel, Stefano Cavalli y Dario Spini (2005). De l'étude des personnes âgées au paradigme du parcours de vie. En D. Mercure (Ed.) L'analyse du social: les modes d'explication (pp. 141-167). Québec: Les Presses de l'Université de Laval.

Denave, Sophie (2015). Reconstruire sa vie professionnelle. Sociologie des bifurcations biographiques, Paris, Presses universitaires de France, colección "Le lien social".

Dirección del Trabajo (2009). Remuneración de vendedores y vendedoras en grandes tiendas. Temas Laborales, Octubre, No. 24.

Dubar, Claude y Sandrine Nicourd (2017). Les biographies en sociologie. Paris: La Découverte.

Durán, Gonzalo y Marcos Kremerman (2014). Los Verdaderos Sueldos de Chile. Panorama Actual del Valor del Trabajo Usando la Encuesta NESI. Documentos de Trabajo del Área de Salarios y Desigualdad. Estudios de la Fundación SOL.

Elster, Jon (2016). Sour Grapes. Studies in the subversion of rationality. Cambridge University press.

Ferreras, Isabelle (2007). Critique politique du travail : Travailler à l'heure de la société des services. Paris: Presses de Sciences Po.

Fillieule, Olivier (2001). Propositions pour une analyse processuelle de l'engagement individuel. Post scriptum, Revue française de science politique, 1(51): 199-215. Doi: 10.3917/rfsp.511.0199.

Fleury, Charles y Hicham Raïq (2013). Présentation : Innovations sociologiques et parcours de vie. Sociologie et sociétés, 45(1): 5-15. doi:10.7202/1016393ar.

Gatica, Sebastián, Waldo Soto y Diego Vela (2015). Ecosistemas de innovación social. El caso de las universidades de América Latina. Publicado por Co-Lab, centro de innovación UC. Santiago, Chile.

García Alonso, Roberto, Ulf Thoene, Ana María Figueroa y Edwin Murillo Amaris (2020). El Emprendimiento Social en el marco de la Alianza del Pacífico. REVESCO. Revista de Estudios Cooperativos, 133.

Grossetti, Michel (2016). Start-up Creators Engaging in Entrepreneurship. Regards croisés sur l'économie, 2(2):14-24. Doi: https://doi.org/10.3917/rce.019.0014.

Grossetti, Michel, Jean-Francois Barthe y Nathalie Chauvac (2018). Les start-up, des entreprises comme les autres ? une enquête sociologique en france, paris, sorbonne université presses, coll. l'intelligence du social. Sociologie économique, 156.

Guzmán, Virginia y Amalia Mauro (2004). Las trayectorias laborales de mujeres de tres generaciones: coacción y autonomía. En R. Todaro y S. Yañez. El trabajo se transforma: relaciones de producción y relaciones de género. Santiago: Centro de Estudios de la Mujer. 
Global Entrepreneurship Monitor (GEM) (2019). Reporte Nacional de Chile. Universidad del Desarrollo, Santiago, Chile.

Henríquez, Helia y Véronica Uribe-Echevarría (2004). La trayectoria laboral de las personas, un aporte al debate sobre la protección al trabajo. Temas Laborales, 8 (20): 1-21.

Hirschman, Albert (1970). Exit, voice and loyalty. Responses to decline in firms, organizations and states. Harvard University Press.

INE (2020). Enfoque de género y microemprendimiento. Documento de análisis. Santiago, Chile.

Kimmitt, Jonathan \& Pablo Muñoz (2018). Sensemaking the 'social' in social entrepreneurship. International Small Business Journal, 36(8): 859-886. Doi: https:// doi.org/10.1177/0266242618789230.

Knox, Stephen. Lucrezia Casulli \& Andrew MacLaren (2021). Identity work in different entrepreneurial settings: dominant interpretive repertoires and divergent striving agendas. Entrepreneurship \& Regional Development. Doi: 10.1080/08985626.2021.1890231.

Kohli, Martin (1989). Le cours de vie comme institution sociale. Enquête, 5. Doi: https://doi.org/https://doi.org/10.4000/enquete.78.

Nicole-Drancourt, Chantal (2009). Un impensé des résistances à l'égalité entre les sexes : le régime temporel. Temporalités, 9, 0-23. Doi: https://doi.org/10.4000/ temporalites.1067.

Martinez, José Luís (2010). The propensity for entrepreneurship: Psychological and social factors. Cuadernos Latinoamericanos de Administración, VI (10): 51-76.

Martinic, Rodolfo (2019). Las encrucijadas del trabajo: una aproximación al escenario laboral de una tienda por departamento. Athenea Digital, 19(3): e2449. Doi: https://doi.org/10.5565/rev/athenea.2449.

Martinic, Rodolfo \& Antonio Stecher (2020). Experiencias de trabajadores del retail en Chile. Aproximación desde la sociología de Dubet. Convergencia, 27. Doi: https://dx.doi.org/10.29101/crcs.v27i0.11939.

Mazade, Olivier (2011). La crise dans les parcours biographiques : un régime temporel spécifique? Temporalités, revue de sciences sociales et humaines, 13.

McDaniel, Susan y Paul Bernard (2011). Life Course as a Policy Lens : Challenges and Opportunities. Canadian Public Policy - Analyse de politiques, xxxvii, supplement/numéro spécial.

Muñoz, Pablo, Jonathan Kimmitt, Tomas Serey y Loreto Velázquez (2016). Reporte estudio: Estructura y dinámica del emprendimiento social en Chile. Estudio desarrollado por CORFO y Universidad del Desarrollo. Impreso en Santiago de Chile. 
Naranjo, Carola (2014). Desigualdades de género en el emprendimiento y en los negocios de las mujeres. Revista Trabajo Social, Pontificia Universidad Católica de Chile. 86.

Negroni, Catherine (2007). Reconversion professionnelle volontaire; changer d'emploi, changer de vie, un regard sociologique sur les bifurcations. Armand Colin. Paris, France.

Paugam, Serge (2007). Le salarié de la précarité. Les nouvelles formes de l'intégration professionnelle. Paris: Presses Universitaires de France.

Pries, Ludger. (1999). Conceptos de trabajo, mercado de trabajo y proyectos biográficolaborales. México.

Ramos, Claudio (2009). La Transformación de La Empresa Chilena: Una Modernización Desbalanceada. Santiago: Ediciones UAH.

Reix, Fabien. et Grossetti, Michel (2014). Parcours biographiques et carrières entrepreneuriales. In Pierre-Marie Chauvin, Michel Grossetti, Pierre-Paul Zalio, Lexique sociologique de l'entrepreneuriat (pp. 413-432). Paris, Les Presses de SciencePo.

Riley, Matilda White (1979). Introduction: Life Course Perspectives. In Aging from Birth to Death, edited by M.W. Riley. Boulder, CO: Westview Press.

Sastre, Raquel (2013). La motivación emprendedora y los factores que contribuyen con el éxito del emprendimiento. Revista Digital de Ciencias Administrativas, Universidad Nacional de la Plata. 1 (1).

Schoof, Ulrich (2006). Stimulating Youth Entrepreneurship: Barriers and incentives to enterprise start-ups by young people. Ginebra: OIT.

Scribano, Adrián (2008). El proceso de investigación social cualitativo. Buenos Aires: Prometeo

Soto, Alvaro, Antonio Stecher \& Pamela Frías (2021). ¿Nuevas orientaciones subjetivas en el trabajo? Los jóvenes de la industria del retail en Chile. Athenea Digital, 21(1): e2772. Doi: https://doi.org/10.5565/rev/athenea.2772.

Spink, Peter (2011). ¿Qué pasó con el trabajo?: de la centralidad de los zapatos, barcos y lacre a los problemas planteados por los cerdos volando. Athenea Digital, 11(3): 3-24.

Stecher, Antonio (2013). "La modernización industrial del retail: Reorganización empresarial y experiencias laborales”. En: Ossandón, J. y Tironi, E. Adaptación. La empresa chilena después de Friedman. Santiago: Ediciones UDP.

Stecher, Antonio \& Rodolfo Martinic (2018). La descualificación del trabajo en tiendas por departamento. Psicoperspectivas, 17(3): 1-12. Doi: http://dx.doi.org/10.5027/ psicoperspectivasvol17-issue3-fulltext-1356. 
Stecher, Antonio y Álvaro Soto Roy (2019). Crisis and transformation of occupational identities in three sectors (retail, mining, state): contributions to understanding workplace subjectivities in neoliberal Chile. Subjectivity, 12, 309-332. Doi: https:// doi.org/10.1057/s41286-019-00080-x.

Strauss, Anselm y Juliet Corbin (2002). Bases de la investigación cualitativa: Técnicas y procedimientos para desarrollar la teoría fundamentada. Antioquía: Editorial de la Universidad de Antioquía.

Suárez Ortega, Magdalena, María Fernanda Sánchez-García \& María Dolores SotoGonzález (2020). Desarrollo de la carrera emprendedora: Identificación de perfiles, competencias y necesidades. Revista Complutense de Educación, 31(2): 173184. Doi: https://doi.org/10.5209/rced.62001.

Todaro, Rosario y Sonia Yáñez (2004). El trabajo se transforma: relaciones de producción y relaciones de género. Santiago: Centro de Estudios de la Mujer.

Undurraga, Rosario (2013). Mujer y trabajo en Chile: ¿qué dicen las mujeres sobre su participación en el mercado laboral? En C. Mora (Ed.), Desigualdad en Chile: la continua relevancia del género (pp. 113-141). Santiago, Chile: Ediciones Universidad Alberto Hurtado.

Undurraga, Rosario \& Paula Cornejo Abarca (2021). Trabajadoras chilenas: identidades en cuestión. Revista Austral de Ciencias Sociales, (40): 197-217. doi:10.4206/ rev.austral.cienc.soc.2021.n40-11.

Weller, Jürgen (2007). La inserción laboral de los jóvenes: características, tensiones y desafíos. Revista de la Cepal, 92, 61-81.

Wormald, Guillermoy María Paz Trebilcock (2015). Trabajo y cohesión social en el ámbito urbano: tensiones y desafíos en la sociedad de mercado chilena. IdeAs5, $2-16$.

Zimmermann, Bénédicte (2014). Ce que travailler veut dire. Une sociologie des capacités et des parcours professionnels. Paris, Economica (2e édition). 


\section{Sobre los autores}

Rodolfo Martinic Lenta es Doctorante en Sociología, École des Hautes Études en Sciences Sociales de Paris (EHESS). Asociado al Núcleo Milenio Autoridad y Asimetrías de Poder, Chile. Temas de investigación: experiencias de trabajo y escenarios laborales en el sector servicios, individuación, sociología del trabajo y de la educación.Correo Electrónico:rodolfomartinic@gmail.com. iD https://orcid.org/0000-00017179-319X

Ismael Tabilo Prieto es Sociólogo de la Universidad Alberto Hurtado, Máster en Ciencias Sociales por l'École des Hautes Études en Sciences Sociales de Paris (EHESS). Académico colaborador de la Facultad de Psicología, Universidad Alberto Hurtado. Temas de investigación: enfoque biográfico y curso de vida, sociología de la educación y el trabajo, transiciones educación-trabajo, métodos de investigación social. Correo Electrónico: itabilo@uahurtado.cl. (D) https://orcid.org/0000-0002-7501-5085 


\title{
CUHSO
}

Fundada en 1984, la revista CUHSO es una de las publicaciones periódicas más antiguas en ciencias sociales y humanidades del sur de Chile. Con una periodicidad semestral, recibe todo el año trabajos inéditos de las distintas disciplinas de las ciencias sociales y las humanidades especializadas en el estudio y comprensión de la diversidad sociocultural, especialmente de las sociedades latinoamericanas y sus tensiones producto de la herencia colonial, la modernidad y la globalización. En este sentido, la revista valora tanto el rigor como la pluralidad teórica, epistemológica y metodológica de los trabajos.

\author{
EDITOR \\ Matthias Gloël \\ COORDINADORA EDITORIAL \\ Claudia Campos Letelier \\ CORRECTOR DE ESTILO Y DISEÑAdOR \\ Ediciones Silsag \\ TRADUCTOR, CORRECTOR LENGUA INGLESA \\ Aurora Sambolin Santiago \\ SITIO WEB \\ cuhso.uct.cl \\ E-MAIL \\ cuhso@uct.cl \\ LICENCIA DE ESTE ARTÍCULO \\ Creative Commons Atribución Compartir Igual 4.0 Internacional
}

